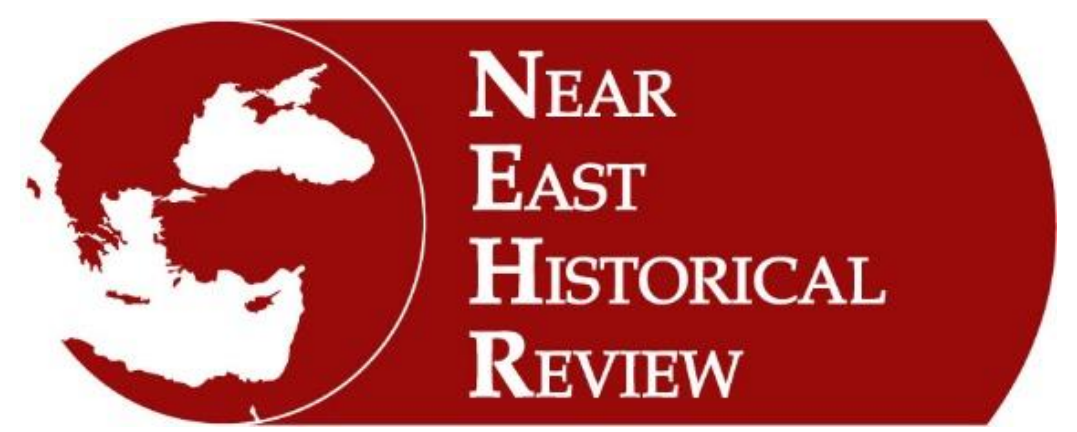

\title{
KALGAY SULTAN ŞAHBAZ GIRAY VE METRÛKÂTI
}

\author{
Kalgay Sultan Shahbaz Giray and His Heritage
}

Zeynep Özdem Köse

Öğr. Gör. Dr., Muğla Sitkı Koçman Üniversitesi,, Türkiye

e-mail: zeynepozdem@mu.edu.tr

ORCID ID: 0000-0002-1745-555X

\section{Near East Historical Review}

\author{
11/4, October / Ekim 2021 \\ e-ISSN: 2717-6363 (Online) \\ www.nehrreview.com
}

\author{
Article Type-Makale Türü : Research Article / Araştırma Makalesi \\ Received Date - Geliş Tarihi : 11.09.2021 \\ Accepted Date - Kabul Tarihi : 10.10 .2021 \\ Pages-Sayfa : $49-62$ \\ doi : http://dx.doi.org/10.29228/nehrreview.55002
}

Citation - Atıf : Zeynep Özdem Köse, "Kalgay Sultan Şahbaz Giray ve Metrûkâtı", Near East Historical Review, 11/4, October, 2021, pp. 49 - 62 



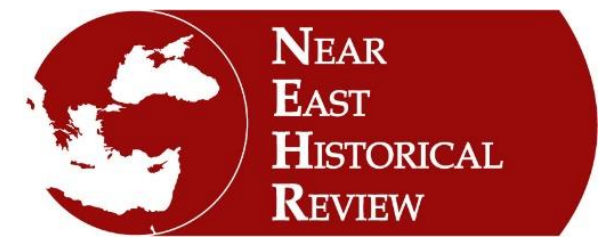

Near East Historical Review

11/4, October - Ekim 2021

49- 62

Research Article - Araştırma Makalesi

\title{
KALGAY SULTAN ŞAHBAZ GİRAY VE METRÛKÂTI
}

\author{
Kalgay Sultan Shahbaz Giray and His Heritage \\ Zeynep Özdem Köse \\ Öğr. Gör. Dr., Muğla Sitkı Koçman Üniversitesi,, Türkiye \\ e-mail: zeynepozdem@mu.edu.tr \\ ORCID ID: 0000-0002-1745-555X
}

\begin{abstract}
Öz
Osmanlı Devleti'ne bağlı Kırım Hanlığı'nda, 17. yüzyılın ikinci yarısında dört defa hanlık tahtına geçip toplam yirmi üç yıl hanlık yapmış Hacı Birinci Selim Giray'ın on iki oğlundan biri olan Şahbaz Giray, kısa süreliğine hanlığın birinci veliahtı konumundaki kalgay sultanlı vazifesini üstlenmiştir. $\mathrm{Bu}$ görevdeyken bir Çerkez kabilesi tarafından şehit edilmiştir.

Bu çalışmada Şahbaz Giray'ın Kırım Hanlığı kadı sicillerinde kayıtlı, vefatının ardından geride bıraktığı emvali incelenmiştir. Böylece hem bir kalgay sultanın mal varlığ 1 hakkında hem de 17 . yüzyılda bölgede kullanılan çeşitli eşyalar hakkında bilgi verilmiştir.
\end{abstract}

Anahtar Kelimeler: Kalgay, Kırım Hanlığı, Sicil, Şahbaz Giray, Tereke

\begin{abstract}
Shahbaz Giray, one of the twelve sons of Hac1 I. Selim Giray, who ascended to the throne of the khanate four times in the second half of the 17th century and served as a khan for a total of twenty-three years in the Crimean Khanate of the Ottoman Empire, assumed the duty of kalgay sultanate, which was the first heir apparent of the khanate for a short time. He was martyred by a Circassian tribe while he was on this duty.

In this study, the properties that he left behind after his death, registered in the kadi records of the Crimean Khanate, were examined. Thus, information was given both about the assets of a kalgay sultan and about various items used in the region in the 17 th century.
\end{abstract}

Keywords: Crimean Khanate, Inheritance, Kalgay (First Heir), Record. Şhahbaz Giray

\section{Giriș}

Kırım Hanlığı Karadeniz'in kuzeyinde, 1441-1783 yılları arasında hüküm sürmüş önemli bir Türk devletidir. Bu devletin hanlarından Hacı I. Selim Giray Han, hanlığın merkezi Bahçesaray'da 1631 yılında dünyaya gelmiş ve 1671-1704 yılları arasında dört defa (1671-1677, 1684-1691, 1692-1699, 1702-1704) Kırım tahtına geçip toplam yirmi üç yıl hanlık yapmış önemli bir Kırım sultanıdır. 17. asrın ikinci yarısında Osmanlı Devleti'nin Rusya, Avusturya ve Lehistan ile yaptı̆̆ı mücadelede Osmanlı Devleti'ne çok büyük yardımları olmuştur. Bu nedenle Osmanlı nezdinde de kıymetli bir handır. On iki oğlu ve on kızı olduğu bilinmektedir ${ }^{1}$. Erkek çocukları Devlet Giray, Azamet Giray, Gazi Giray, Kaplan Giray, Saadet Giray, Mengli Giray, Safa Giray, Adil Giray, Selamet Giray, Maksud Giray, Sahib Giray ve Şahbaz Giray’dı².

Selim Giray'ın erkek çocuklarından bazıları Kırım hanına veliahtlık görevinde bulunmuştur. Devlet Giray, Azamet Giray, Gazi Giray, Kaplan Giray, Maksud Giray, Mengli Giray, Sahib Giray ve Şahbaz Giray bunlar arasındadır. Bu giraylardan altısı hanlık tahtına da

\footnotetext{
${ }^{1}$ H. Mustafa Eravc1, "Selim Giray", DIA, XXXVI, s. 428.

${ }^{2}$ Halîm Girây, Gülbin-i Hânân (Kırım Tarihi), Haz. İbrahim Gültekin, Ankara 2019, s. 116, 133.
} 
oturmuştur. Bu isimler ise Devlet Giray, Gazi Giray, Kaplan Giray, Saadet Giray, Mengli Giray ve Selamet Giray'dır'.

Hac1 I. Selim Giray Han'ın 1699'da hanlıktan çekilmesi üzerine oğlu Devlet Giray han olmuștur. Devlet Giray, kardeșlerinden Şahbaz ${ }^{4}$ Giray Sultan'1 kalgay ve Gazi Giray Sultan'1 nureddin tayin etmiştir ${ }^{5}$. Şahbaz Giray'ın vazifesi daha önemlidir; çünkü kalgay sultan tahtın varisi ilk kişi demektir.

Hacı Selim Giray gibi evlatları da düşmana karşı büyük mücadeleler vermişlerdir. Şahbaz Giray da bunlar arasındadır. Örneğin kalgay sultan 1694-1695 (H. 1106)'te Kamaniçe Kalesi'ne buğday götürürken önüne çıkan Leh askerine mağlup olmuş ve buğdayı tamamen düşmana terk etmek zorunda kalmıştır. Ertesi yıl 1695-1696 (H. 1107)'da, Şahbaz Giray kuvvetli bir ordu ile gidip mağlubiyetin intikamını Lehlilerden almıştır 6 .

Şahbaz Giray Çerkez asileri ile de mücadele etmiştir. Ancak onların eline esir düşerek şehit olmuştur. Hatta bunun üzerine kalgaylık makamına Saadet Giray Sultan'ın getirilmesi Gazi Giray Sultan'1 gücendirmiş ve onun Bucak tarafina gidip Devlet Giray Han'a karşı isyan etmiş olan Nogay kabilesine iltihak etmesine neden olmuştur ${ }^{7}$. Kaplan Giray da Besleni Kabilesi tarafindan şehit edilen Şahbaz Giray'ın intikamını almak içini hanın ve kalgayın rızalarını elde ettikten sonra bir miktar asker ile kabilenin üzerine gidip onları mağlup ettikten sonra onlara karşı çok şiddetli davranmıştır. Han Devlet Giray ise bu kabilenin taht-1 terbiyelerinde büyümüş olduğundan onlara yapılan bu zulümden müteessir olmuş ve Kaplan Giray’ı bu hareketinden dolayı azarlamıştır. Hanın bu muamelesini gençlik gururuna yediremeyen Kaplan Giray Kırım'1 terk edip babasının yanına çekilmiştir ${ }^{8} .1707$ senesinde Kırım hanı olan Kaplan Giray bir sene sonra, Çerkez nizamındaki başarısızlığı, özellikle merhum Şahbaz Giray ve kendisinin Kabartay hududunda meydana gelen muharebede hezimete uğrayıp nice ayan u ümeranın şehadetine sebebiyet vermesi gibi sebepler üzerine 1708 'de azledilip Rodos'a sürülmüştür'. Daha sonraki y1llarda yeniden han olacaktır ${ }^{10}$.

Görüldügü üzere II. Devlet Giray Han'ın birinci saltanatı döneminde (1699-1702) kalgay sultanlık vazifesine layık görülen Şahbaz Giray yaklaşık bir sene bu görevi ifa edebilmiş, batıda Lehlere, Kafkaslarda Çerkezlere karşı mücadele vermiş, bazı muvaffakiyetsizlikler yaşamış ve sonunda bir Çerkez kabilesi tarafından da şehit edilmiştir. Vefat tarihi 1700 (H. 1112) senesinin başlarıdır.

\footnotetext{
${ }^{3}$ Hanların şeceresi için bkz. Halîm Girây, age, s. 41-45.

${ }^{4}$ Şahbaz Farsça kökenli bir isimdir. Mert, yürekli anlamlarını taşımaktadır. Kahramanlık, kuvvet ve cesaretin sembolü olan hayvanların adlarını insanlara tatbik etmek suretiyle verilen adlar arasındadır. Kurt, Kaplan, Arslan örneklerindeki gibi. Şahbaz, şahin-doğan kuşları anlamına gelmektedir. Bkz. Bülent Gül, "Kırım-Tatar Türklerinde Kişi Adları", Türkbilig, S: 2, Ankara 2001, s. 57-59.

${ }^{5}$ Halîm Girây, age, s. 126.

${ }^{6}$ Halîm Girây, age, s. 127.

${ }^{7}$ Halîm Girây, age, s. 126.

${ }^{8}$ Halîm Girây, age, s. 127.

${ }^{9}$. Halîm Girây, age, s. 133

101713 yılında II. Devlet Giray Han azledilince I. Kaplan Giray, Rodos'tan çağırılarak ikinci kez Kırım hanı tayin edilmiştir. 1716 senesinde Avusturya seferine katılma emri almıştır. Fakat Kırım kuvvetlerinin sefere geç kalmasından dolayı Varadin Muharebesi'ndeki yenilgiden Kaplan Giray sorumlu tutulmuştur. Bunun sonucunda tekrar hanlıktan azledilmiştir. Ardından 1730 senesinde üçüncü kez Kırım hanı olarak tayin edilmiştir. 1736 yılında da azledildikten sonra Sakız Adası'nda ikamete memur edilmiş ve 1738'de burada vefat etmiştir. Vasiyeti üzerine Çeşme'ye defnedilmiştir. Bkz. Müstecib Ülküsal, Kırım-Türk Tatarları (Dünü-Bugünü-Yarını), İstanbul, 1980, s. 82, 86.; Halil İnalcık, Kırım Hanlığ Tarihi Üzerine Araştırmalar 1441-1700, İstanbul 2017, s. 351, 354; Özge Togral, "Akdeniz Adalarına Sürgün Edilen Kırım Hanları”, Mediterranean Journal of Humanities, VIII/1, (2018) , s. 360.
} 
Kırım Hanlığı şeriyye sicilleri sayesinde Şahbaz Giray'ın metrûkâtı tespit edilmiştir. Böylece sultanın vefatından sonra geride bıraktığı malları inceleme imkânı elde edilmiştir. Bir Kırım hanının evladı, bir kalgay sultan ve dolayısıyla Giraylar sülalesine mensup biri olarak nelere sahip olduğu hakkında bilgi sahibi olunmuştur. Böylece 17. asırda kullanılan eşyalar, silahlar, takılar, mücevherler vb. hakkında da bilgi edinilmektedir. Daha önce inceleme yapılan kardeşi Azamet Giray’ın terekesi ile karşılaştırma yapma imkânı da ortaya çıkmıştır.

\section{1. Şahbaz Giray Sultan'ın Terekesi}

Kalgay Sultan Şahbaz Giray 1700 (H. 1112) senesi başlarında vefat etmiştir. Geride bıraktığı mal varlığı toplam 7792,65 guruştur. Terekesinde köleler, mücevherat, takılar, silahlar, atlar, çeşitli kıyafetler, mutfak ve ev eşyaları bulunmaktadır. En değerlileri arasında altmış bin akçe kıymeti ile çengi kız ilk sırada, elli beş bin akçe değerindeki kırmızı çuha samur kürk de ikinci sırada yer almaktadır. Onları diğer köleler, kürkler, hançerler ve at takımları takip etmektedir.

Şahbaz Giray'ın terekesinde alacağı vardır; ancak borcu o kadar fazladır ki küçük miktardaki bu alacağı ve diğer bütün mal varlığı borçlarını kapatmak üzere alacaklılara dağıtılır.

\subsection{Köleler}

Şahbaz Giray'ın terekesinde şahsına ait beşi kadın, ikisi erkek olmak üzere yedi kölesi mevcuttur. Bunlardan ikisinin emaneten başkalarına verildiği anlaşılmaktadır. Kadın kölelerden çengi kız olarak kayıtlı olanın eğlencelerde dans etme amaçlı istihdam edildiği anlaşılmaktadır. Değeri en yüksek olan köle de budur.

Tablo 1: Köleler

\begin{tabular}{|l|l|}
\hline Köle Adı & Değeri (Akçe) \\
\hline Süleyman Ağa & 40.000 \\
\hline Hasan gulam & 20.000 \\
\hline Çengi kız & 60.000 \\
\hline Mihri kız & 15.000 \\
\hline Gülen (?) cariye & 27.500 \\
\hline Hafızoğlu'nda kız & 8000 \\
\hline Arslan Gazi Bölükbaşı'nda bir kız & 15.400 \\
\hline
\end{tabular}

\subsection{Kıyafetler}

Kalgay Sultan'in terekesinde kürk, ihram, kolçak, kuşak, hamam gömleği ve bohçasından oluşan kıyafetleri kayıtlıdır. Bunlar arasında sincap, as, samur, kakum ve tilki derisinden yapıl1, kıymeti hayli yüksek olan kürkler dikkati çekmektedir. Tereke içerisinde meblağı en yüksek mallar arasında yer almaktadırlar. Bunların haricinde dikimi beklenen samur, kunduz, sincap, tilki pareleri, sarı sahtiyan, mor meşin ve telatin de bulunmaktadır.

Kıyafetlerde deriden başka çuha, boğası, keten, kebe gibi kumaşlar da kullanılmaktadır. Şahbaz Giray’ın terekesinde kayıtlı kıyafetleri tablo halinde göstermek mümkündür. 
Tablo 2: Kiyafetler

\begin{tabular}{|l|l|}
\hline Kıyafet & Değeri (Akçe) \\
\hline As kürkü & 6500 \\
\hline İki sincap kürkü & 3100 \\
\hline Kırmızı çuha samur kürk & 55.000 \\
\hline Keşmiri zarflı samur kürk & 30.000 \\
\hline Yeşil zarflı samur kürk & 25.000 \\
\hline Kırmızı zarflı kakum kürk & 10.000 \\
\hline Siyah tilki kürkü & 18.000 \\
\hline Büyük ihram & 5000 \\
\hline İki ihram & 7000 \\
\hline Bir ihram & 3500 \\
\hline Bir ihram & 2000 \\
\hline Zerbab kuşak & 800 \\
\hline Keşmiri kuşak & 1250 \\
\hline Hamam gömleği bohçasılyla & 1000 \\
\hline Misır kolçağ1 & 13.000 \\
\hline
\end{tabular}

\subsection{Silahlar, Atlar ve At Takımları}

Şahbaz Giray'ın terekesinde at ve silahlar da yer almaktadır. Şahbaz Giray'ın bulunduğu konum nedeniyle, yüksek meblağglı terekelerde olduğu gibi farklı cinslerde çok sayıda at sahibi olduğu düşünülmektedir. Fakat terekede sadece yedi bin sim akçe değerinde bir adet kaşka atı olduğu tespit edilmiştir. Ancak daha önceden at satışlarının yapıldığı da anlaşılmaktadır. Nitekim Hacı Ali Ağa'dan alınacak dört bin sim at akçesi kalmıştır.

Silahlar hançer, kılıç, yay, ok ve çeşitli amaçlarla kullanılan urgandır. At takımları ise hem çeşitli hem de yüksek meblağlıdır.

Tablo 3: Silahlar ve At Takımları

\begin{tabular}{|l|l|}
\hline Silahlar ve At Takımları & Değeri (Akçe) \\
\hline Üç hançer & 100.000 \\
\hline Tiğ (k1lıç) & 700 \\
\hline Kavis kirişi (yay kirişi) & 12 \\
\hline Urgan & 10 \\
\hline Gaddâre (kılıç) & 750 \\
\hline Yeşil kaytanlı raht sînebendli eyeri ve gediğiyle gümüş üzengi ${ }^{11}$ & 25.000 \\
\hline Kırmızı kaytanlı sînebendi ve reşmesiyle eyeri ve gediği gümüş üzengi & 25.000 \\
\hline Yaldızlı üzengili eyer ve gediği ve raht ve sînebendiyle & 10.000 \\
\hline
\end{tabular}

\footnotetext{
${ }^{11}$ Kaytan, raht, reşme (rişme), sîne-bend, eyer, üzengi vb.at binit takımının birer parçasıdır. Bu konuyla ilgili detaylı bir çalışma için bkz. Emine Dingeç, "18. Yüzyılın İkinci Yarısında Saray Atlarının Binit Takımları", Uludăg Üniversitesi Fen-Edebiyat Fakultesi Sosyal Bilimler Dergisi, Y11: 12, S: 20, 2011, s. 1-20.
} 


\subsection{Ev ve Mutfak Eşyaları}

Terekede ayrıca Şahbaz Giray'a ait çeşitli ev eşyaları da bulunmaktadır. Bu eşyalar yastıklar, yorganlar, döşekler, peşkirler, makatlar, perdeler, minderler, halılar, kilimler, hasırlar, heybeler, bohçalar, sandıklar, leğenler, ibrikler, gügümler, lengerler, kazanlar, kapaklar, tavalar, makaslar, şamdanlar, saclar, gülabdanlar, buhurdanlar, maşrabalar, kaşıklar, siniler, tabaklar ve tömbeki terekede kayıtlı ev ve mutfak eşyaları arasında yer almaktadır. Bu eşyalardan mutfakta kullanılanlar büyük, küçük, kapaklı, kapaksız, kulplu, kulpsuz, yaldızlı oluşlarına ve kullanılış amaçlarına göre isimlendirilmiştir. Örneğin beş sahan kapağıyla, küçük güğüm, büyük lenger hoşaf tası kapaklı, iki kazan kulplu, yaldızlı maşraba, yaldızlı leğen ibrik.

Ev eşyalarında da büyük, küçük, eski (köhne), yeni (cedid) oluşlarına, renklerine, yapılış şekillerine, kumaş cinslerine, kullanılış amaçlarına ve üretim yerlerine göre bir isimlendirme mevcuttur. Örneğin kapı perdesi, işleme minder, küçük halı, büyük orta makad, iki yan makatı, bir çift sarı yan kebesi, dört yüz yastığı, köhne kırmızı kilim, orta halı cedid, beyaz peşkir, altı çift çatma yastık, beş çift dolma yastık, iki çift yeşil kadife yastık, yeşil pervazlı makad, kırmızı peşkir, iki döşek İslambol basma, iki Mısır hasırı, Herat alacası, siyah Hatayi boğası, üç tek Türkmen kilimi.

\subsection{Alacakları ve Borçları}

Şahbaz Giray öldüğünde bir kişiden alacağı ve farklı kişilere borçları olduğu tespit edilmiştir. Alacağı dört bin akçe tutarında olup Hacı Ali Ağa'da olan at akçesidir. Terekenin \% 0,5'ine tekabül etmektedir. Borç defteri ise oldukça kabarıktır. Terekesindeki bütün mallar borçlarına karşılık alacaklılara verilmek üzere kaydedilmiştir. Hangi malın kime verileceği ve tek tek borç miktarı bellidir. Borçlu olduğu kişiler arasında İbrahim Ağa, Mehmet Molla, Ahmet Molla, Hacı Ahmet, Acem Karaoğlan, Acem Sefer, Eyüpoğlu Mustafa Çelebi, Haçader zımmi, iki Yahudi, Adilşah, Seyfullah Molla, Arslan Gazi, Tamanlı Sefer Ali, Tamanlı Hasan Ağa, Hacı Süleyman, Mustafa Beşe, Zabit Ahmet, Hatib Abdurrahman Efendi, Ahmet Ağa, Devletgazi, Ali Ağa, Attar Hacı Mahmut, Sarracbaşı Derviş, Sefer Gazi, Halil Sekban, Karagöz Mirza, Arslan Efendi, Ali Bölükbaşı ve Terzi Kantimur yer almaktadır. Borçlu olduğu kişilerin efendi, molla, mirza, hacı unvanlı kişiler ile asker ve esnaf kesiminden oldukları anlaşılmaktadır. Alacaklılar listesinde Yahudi ve Ermeniler de vardır ${ }^{12}$.

\section{Sonuç}

Kırım Hanı II. Devlet Giray zamanı, 1699-1700 yılları arasında, çok kısa bir süre birinci veliaht konumundaki kalgay sultanlık vazifesinde bulunmuş olan Şahbaz Giray'ın mal varlığının o dönemki tereke miktarlarıyla kıyaslandığında geliri yüksek sınıfların içerisine girdiğini söylemek mümkündür. Ancak bir kalgay sultan olarak sürü halinde hayvanlarının ve gayrimenkullerinin bulunmayışı ilginçtir. Ayrıca Şahbaz Giray'ın cesareti ve mertliği yanında ehl-i keyf bir yapıda olduğu tahmin edilebilir. Tütüne olan düşkünlügü, Çengi kız ve birikmiş borçları buna işaret olabilir.

Terekesi kardeşi Azamet Giray'ınki ile kıyaslandığında onun dokuz bin guruş değerindeki terekesine göre daha düşük miktardadır. Azamet Giray'ın terekesinde de sürü halinde hayvanlar ve gayrimenkuller bulunmamaktadır. Yedi kölesi mevcuttur ve hepsini hayatta iken azat etmiştir. Terekesindeki borç miktarı \% 36,7 olup üstelik bunun \% 30,6's1 zevcesine olan

\footnotetext{
${ }^{12}$ Şahbaz Giray'ın borçlu olduğu kişiler, borç miktarları ve buna karşılık terekeden verilen malların tam listesi için bkz. $K S S S, 34,12-17$ (a-b).
} 
mehir borcudur ${ }^{13}$ ki bu hemen hemen her terekede görülmektedir. Ancak Şahbaz Giray'ın bütün mal varlığı borçlarına gitmiştir.

Terekede ev ve mutfak eşyalarının sayı ve çeşidinin kıyafetlere göre daha fazla olduğu tespit edilmiștir. Kullanılan bu eșyalar arasında Türkmen kilimi, İslambol basması, Rus derisi (telatin), Mısır hasırı, Mısır kolçağı, Keşmirî kuşak ve Herat alacasının varlığı Kırım'ın canlı ticaret hayatı ve kozmopolit yapısını da göstermektedir ${ }^{14}$.

Terekenin \% 23,8'ini köleleri, \% 23,2'sini kıyafetleri, \% 20,7'sini silahları ve at takımları oluşturmaktadır. Kalan 32,3'lük kısım çeşitli ev ve mutfak eşyalarından meydana gelmektedir. Ayriyeten sahip olduğu bir kaşka at da bu grubun içerisindedir.

\section{Kaynakça}

\section{Arşiv Belgeleri}

KŞS: Kırım Hanlığı Şeriyye Sicilleri, Cilt/Defter No: 34, Yı1: H. 1110-1112 / M. 1698-1700, 116s., mikrofilm, İsmail Gaspıralı Kütüphanesi, Simferopol-Kırım.

\section{Kaynak Eserler}

Halîm Girây, Gülbin-i Hânân (Kırım Tarihi), Haz. İbrahim Gültekin, T.C. Kültür ve Turizm Bakanlığ1 Yay., Ankara 2019.

\section{Araștırma ve İncelemeler}

Dingeç, Emine, “18. Yüzyılın İkinci Yarısında Saray Atlarının Binit Takımları”, Uludă Üniversitesi Fen-Edebiyat Fakültesi Sosyal Bilimler Dergisi, Y11: 12, S: 20, 2011, s. 1-20.

Eravc1, H. Mustafa, "Selim Giray", Türkiye Diyanet Vakfi İslam Ansiklopedisi, XXXVI, İstanbul 2009, s. 428-429.

Gül, Bülent, "Kırım-Tatar Türklerinde Kişi Adları”, Türkbilig, S: 2, Ankara 2001, s. 55-60.

İnalcık, Halil, (2017). Kırım Hanlığı Tarihi Üzerine Araştırmalar 1441-1700. Türkiye İş Bankası Kültür Yay., İstanbul 2017.

Özdem Köse, Zeynep, “Kırım Sultanlarından Cennethan Biyim'in Muhallefâtı (17. Yüzyılın İkinci Yarısı)", Başlangıcından Günümüze Türk Tarihinde Kadın, ed. Hakan Doğan, Berikan Yay., Ankara 2021, s. 133-141.

Özdem Köse, Zeynep, “Osmanlı Kültürel Coğrafyası Çerçevesinde Kırım Hanı I. Selim Giray’ın Oğlu Nureddin Azamet Giray Sultan'ın Muhallefâtı”, Osmanlı Tarihî Coğrafyası Üzerine Araştırmalar, ed. Fatma Ünyay Açıkgöz, Hakan Doğan, Berikan Yay., Ankara 2020, s. 373-396.

Şemseddin Sami, Kâmûs-ı Türkî, Çağrı Yay., İstanbul 1999.

\footnotetext{
${ }^{13}$ Zeynep Özdem Köse, “Osmanlı Kültürel Coğrafyası Çerçevesinde Kırım Hanı I. Selim Giray’ın Oğlu Nureddin Azamet Giray Sultan'ın Muhallefâtı”, Osmanlı Tarihî Coğrafyası Üzerine Araştırmalar, ed. Fatma Ünyay Açıkgöz, Hakan Doğan, Berikan Yay., Ankara 2020, s. 382, 394.

${ }^{14}$ Hacı Selim Giray'ın oğullarından Azamet Giray Sultan'ın terekesinde Acem, Çerkez, Boğdan, Şam, Keşmir, Rus, Çin, Tire, Mardin, Sakız, Cezayir ve Rumeli işine rastlanılmıştır. Bkz. Özdem Köse, agm, s. 394. Yine Hacı Selim Giray'ın zevcesi Cennethan Biyim'in metrûkâtında da Yemen, Hint, Trakya, Selanik, Mısır, Çin, Avrupa (Frengî) ve Anadolu işi ürünler mevcuttur. Bkz. Zeynep Özdem Köse, "Kırım Sultanlarından Cennethan Biyim'in Muhallefâtı (17. Yüzyılın İkinci Yarısı)", Başlangıcından Günümüze Türk Tarihinde Kadın, ed. Hakan Doğan, Berikan Yay., Ankara 2021, s. 139.
} 
Togral, Özge, “Akdeniz Adalarına Sürgün Edilen Kırım Hanları”, Mediterranean Journal of Humanities, VIII/1, (2018), s. 355-366.

Ülküsal, Müstecib, Kırım Türk-Tatarları (Dünü-Bugünü-Yarını), Baha Matbaası Yay., İstanbul 1980.

İnternet Sitesi

http://lugatim.com/ Kubbealtı Lugatı (Kasım-Aralık 2021).

\section{Ek-1}

\section{Şahbaz Giray Sultan'ın Şeriyye Sicilinde Kayıtlı Terekesi ${ }^{15}$}

1. Yeşil pervazli ${ }^{16}$ çuha makad ${ }^{17}: 3300 \operatorname{sim}^{18}$

2. Yeşil pervazlı bir çift kızıl makad: $6500 \mathrm{sim}$

3. Defan yeşil pervazlı bir çift kızıl makad: 7000 sim

4. Defan yeşil pervazlı tek makad: $3500 \mathrm{sim}$

5. Siyah pervazlı makad: 3100

6. Yeşil pervazlı makad: 2000

7. Sarı pervazlı makad: 1200

8. Köhne kırmızı makad sâde: 600

9. Üç tek Türkmen kilimi: 2800

10. Beş döşek, yirmi yastık: 4344

11. Beş çift dolma yastık: 16.500

12. Altı çift çatma yastık: 8000

13. İki çift yeşil kadife yastık: 1200

14. Üç kırmızı kadife yastık: 600

15. Beyaz peşkir: 1000

16. İki peşkir: 300

17. Altı döşek: 2340

18. İki döşek İslambol basma: 900

19. İki yayma basma: 1900

20. Kapı perdesi: 500

21. Defan kapı perdesi: 300

22. İki küçük yayma: 700

23. Büyük yayma basma: 1000

24. Küçük yayma basma: 700

25. Küçük yayma basma: 300

26. Defan basma yayma: 600

27. Dört yüz yastığı: 550

28. İşleme minder: 400

29. İ̉i kuş yünü yastık: 280

\footnotetext{
15 Şahbaz Giray Sultan'ın şeriyye sicilinde yer alan tereke kaydına, emvalin dökümü verilmeden evvel, şu şekilde başlanılmıştır: "Oldur ki merhum ve mağfurun-leh Şahbaz Giray Sultan aleyhirrahmetü ve'l-ğufrân hazretlerinin metrûkâtı beyân olunur.” Bkz. KŞS, 34, 18a-b, 19a-b, 20a.

${ }^{16}$ Kumaştan yapılmış kimi eşyaların kenarlarına geçirilmiş dar ve uzun parça.

${ }^{17}$ Makatın üç anlama geldiği görülmektedir. Birincisi oturulacak yer, ikincisi oturmak için kullanılan minder üzerine yayılan, ön kenarı saçaklı örtü, üçüncüsü alçak sedirdir.

${ }^{18}$ Terekede belirtilen bütün eşyaların değeri sim akçe üzerinden verilmiştir. Bu nedenle hepsine tek tek belirtme gereği duyulmamıştır. Parantez içerisinde belirtilenler terekede mevcut değildir. Açıklama olması açısından verilmiştir.
} 
30. Büyük orta makad: 13.550

31. Bir çift mai (mavi) kebe ${ }^{19}: 1600$

32. Bir çift alaca (karışık renkli) yan kebesi: 600

33. Bir çift sarı yan kebesi: 1700

34. Küçük halı: 1600

35. Köhne halı: 1500

36. Kirmiz1 orta makad: 5500

37. Defan kırmızı orta makad: 5000

38. Mai orta makad: 1500

39. İki yan makadi: 1100

40. Orta halı, cedîd: 3500

41. İki Misır hasır: 400

42. Köhne kırmızı kilim: 120

43. Ocak döşemesi: 120

44. Kösele (işlenmiş deri) sofra: 95

45. İki keçe: 130

46. İki keçe, bir siyah bir beyaz: 200

47. Defan iki keçe: 150

48. Pâre keçe: 10

49. Küçük yüz yastığı: 50

50. Beş sahan kapağıyla: 1400

51. Defan beş sahan kapağıyla: 1720

52. Defan beş sahan kapaklı: 2082

53. Defan beş sahan kapaklı: 2205

54. Defan beş kapaklı sahan: 1776

55. Defan beş kapaklı sahan: 1806

56. Leğe, ibrik, güğüm: 1223

57. Bir güğüm: 450

58. Kapaksız altı sahan: 1531

59. Küçük gügüm: 350

60. Beş büyük lenger sahan kapakl1: 4300

61. Defan beş büyük lengerî kapakl1: 3920

62. İki lenger sahan kapağıyla 1592

63. Büyük lenger hoşab (hoşaf) tası kapaklı: 1000

64. Defan üç lengeri kapağıyla: 2082

65. Şamdan mea mikras (makas): 160

66. Üç leğen mea hurda bakır: 2040

67. Mum sofrası mea satır, iki tabak: 120

68. İki kazan kulplu: 2200

69. İk tencere kazan: 950

70. Saç ve kazan tâbe (tava): 1700

71. Bir kazan: 450

72. Samdan: 100

73. Âs (kakum denilen bir hayvan) kürkü: 6500

74. İki sincap kürkü: 3100

75. İki kunduz: 300

76. İki Hatayî mai: 3100

77. Verayi bab (?): 2225

${ }^{19}$ Çok kalın keçe. 
78. Peşkir Sakızî: 2500

79. Zerbâb ${ }^{20}$ kuşak: 800

80. İki kahve peşkiri: 2050

81. Hamam gömleği bohçasıyla: 1000

82. Bir kita basma mea boğas ${ }^{21}: 100$

83. Keşmirî kuşak: 1250

84. İki ağaç çuha: 600

85. Dühan kese işleme: 280

86. Kol yüz bezi: 66

87. Dört çift samur: 12.000

88. Alaca peşkir: 275

89. Gazi verayi (?) : 550

90. Beyaz Hindî: 350

91. Beyaz boğası: 300

92. Defan beyaz boğası: 300

93. Alaca: 350

94. Beyaz boğası: 405

95. Defan beyaz boğası: 410

96. Alaca boğası: 240

97. İki boğası: 900

98. Boğas1: 450

99. Alaca: 650

100. Alaca kutnîi22: 805

101. Alaca kaplan: 800

102. İki gazi verayi (?) : 1200

103. Gazi verayi (?):570

104. Keten: 600

105. Herat alacas1: 700

106. Alaca boğasi: 250

107. Kunduz: 1060

108. Dört çift kunduz pâresi: 1010

109. Siyah Hatayî boğası: 500

110. Siyah Hatayî pâresi: 570

111: Tömbekîî23: 225

112. Defan tömbekî:230

113. Pâre samur: 1000

114. Beş bohça: 210

115. Tuğ verayisi : 400

116. Pik ve ibrișim ${ }^{24}: 810$

117. Altı miskal kılabdan ${ }^{25}: 240$

118. Kumaş pâresi: 220

119. Köhne peşkir: 106

\footnotetext{
${ }^{20}$ Sirma ile dokunmuş kumaş.

${ }^{21}$ Astarlık ince, pamuklu bez.

22 İpek-pamuk karışımı bir kumaş çeşididir.

${ }^{23}$ Nargile ile içilen bir tütün çeşididir.

${ }^{24}$ Pik, gemilerin kıç tarafındaki bayrak serenine asılan üçgen yelken ve dökümle şekillendirilebilen demir külçesi anlamlarına gelmektedir. İbrişim ise bükülmüş ipekten ipliktir.

${ }^{25}$ Eğirme çark1 ile pamuk ipliği veya ipek üzerine gümüş, altın, bakır vb. madenlerden çekilmiş çok ince tellerin sarılması sûretiyle yapılan ve dokumacılıkta, işlemecilikte kullanılan ipliktir.
} 
120. On göçgen ${ }^{26}$ kuyruğu: 600

121. Altı dirhem karanfil: 20

122. Kebutî ( gök rengi, mavi) deri: 440

123. Karûre (şişe) tepsisi: 100

124. Yirmi sekiz kaşık: 1200

125. Teşt mea kapak: 120

126. İki göbek misk: 1225

127. Bir yeşil, bir mor kahve peşkiri: 1225

128. On deste kâğıt: 200

129. İki yay: 2000

130. Sincap: 1000

131. İki telatin ${ }^{27}: 625$

132. Köhne kırmızı peşkir: 400

133. İki pâre tilki: 1700

134. Sarı sahtiyan: 100

135. Mor meşin: 60

136. Üç zirâ‘ bez: 30

137. Zerdeva ${ }^{28}: 2500$

138. Şamdan mea mikras: 150

139. Küçük şamdan: 100

140. Heybe: 25

141. Büyük leğen: 1100

142. Büyük gügüm: 385

143. İbrik: 235

144. İki neftî kebe: 1015

145. Kırmızı peşkir: 1000

146. Basma yayma: 520

147. İki sini: 5400

148. Kavis kirişi (Yay kirişi): 12

149. Urgan: 10

150. Yaldizlı fener: 1500

151. Yaldızlı, kapaklı teşt küçük tabak: 230

152. Yaldızlı maşraba: 185

153. Yaldızlı leğen ibrik: 2700

154. Defan yaldızlı leğen ibrik: 2650

155. Yeşil kaytanlı raht sînebendli eyeri ve gediğiyle gümüş üzengi: 25.000

156. Kırmızı kaytanlı sînebendi ve reşmesiyle eyeri ve gediği gümüş üzengi: 25.000

157. Yaldızlı üzengili eyer ve gediği ve raht ve sînebendiyle: 10.000

158. Üç hançer: 100.000

159. Kırmızı çuha samur kürk: 55.000

160. Keşmirî zarflı samur kürk: 30.000

161. Yeşil zarflı samur kürk: 25.000

162. Kırmızı zarflı kakum kürk: 10.000

163. Bohça: 100

164. Gülabdan mea buhurdan (35 dirhem): 76665

165. Sandik: 200

${ }^{26}$ Tavşan yavrusu, benekli tavşan, kır sansarı.

${ }^{27}$ Ayakkabı, çizme vs. yapılan sağlam ve yumuşak Rus derisidir.

${ }^{28}$ Zerdava olarak da kullanılan bu kelime, İskandinavya ve Rusya'nın buzlu bölgelerinde yaşayan, sansar cinsi, küçük, etçil, memeli hayvan ve bu hayvanın postundan yapılan kürk anlamlarına gelmektedir. Terekedeki anlamı kürktür. 
166. Misır kolçak: 13.000

167. İki bohça: 200

168. Büyük ihram: 5000

169. İki ihram: 7000

170. Bir ihram: 3500

171. Defan ihram: 2000

172. Siyah tilki kürk: 18.000

173. Gaddâre' ${ }^{29}: 750$

174. Hasan gulam: 20.000

175. Haçader'e geçmiş (?): 17.500

176. Hac1 Ali Ağa'da at akçesi: 4000

177. Süleyman Ağa: 40.000

178. İki kadeh: 650

179. Çengi ${ }^{30}$ kız: 60.000

180. Hafizoğlu'nda k1z: 8000

181. Arslan Gazi Bölükbaşı'nda bir kız: 15.400

182. Gülen (?) cariye: 27.500

183. Mihri kız: 15.000

184. Kaşka at: 7000

185. İki topluğu: 200

186. Kozak ${ }^{31}$ bal mum: 20

187. Bir kita basma: 25

188. Defan bir kita basma: 25

189. Tiğ (k1lıç): 700

Ceman sim: 779,265 (7792,65 esedi guruş)

\footnotetext{
${ }^{29}$ Geniş yüzlü ağır ve iki tarafi da keskin kılıç.

${ }^{30}$ Def, zil veya kaşık çalarak oynayan oyuncu kadın, rakkâse.

${ }^{31}$ Kozalak da aynı anlama gelmekte olup kelimenin birinci anlamı, içine padişahın mektup ve emirlerinin, anlaşmaların konulduğu kutudur. İkinci olarak ise bal mumuna basılmış mührün bozulmaması için üzerine kapanan kapakçık anlamına gelmektedir.
} 
Ek-2 Şahbaz Giray Sultan'ın Terekesi (KŞS, 34, 18a-b, 19a-b, 20a.)

\section{0}

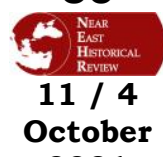

2021

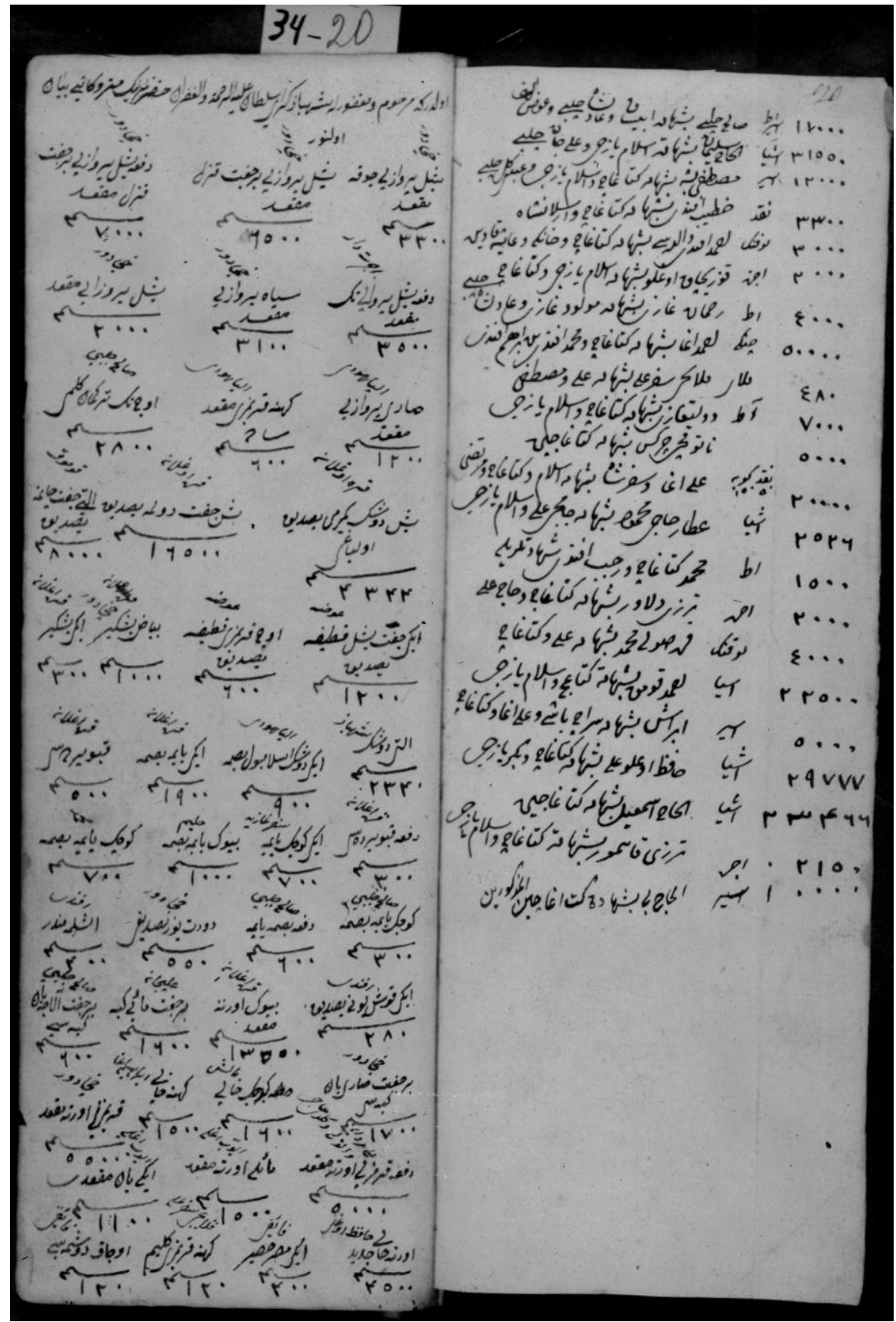

Near East Historical Review

www.nehrreview.com 


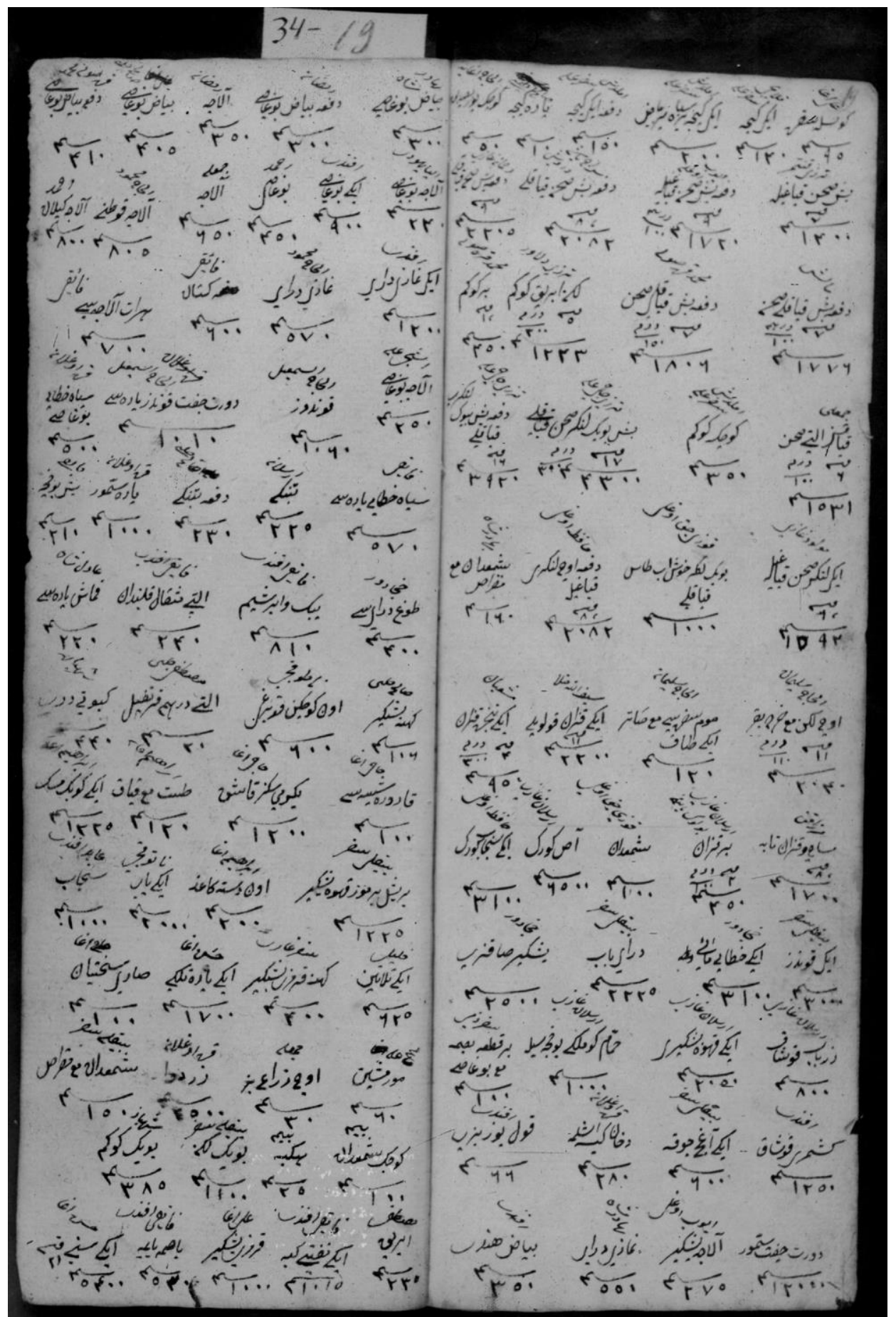




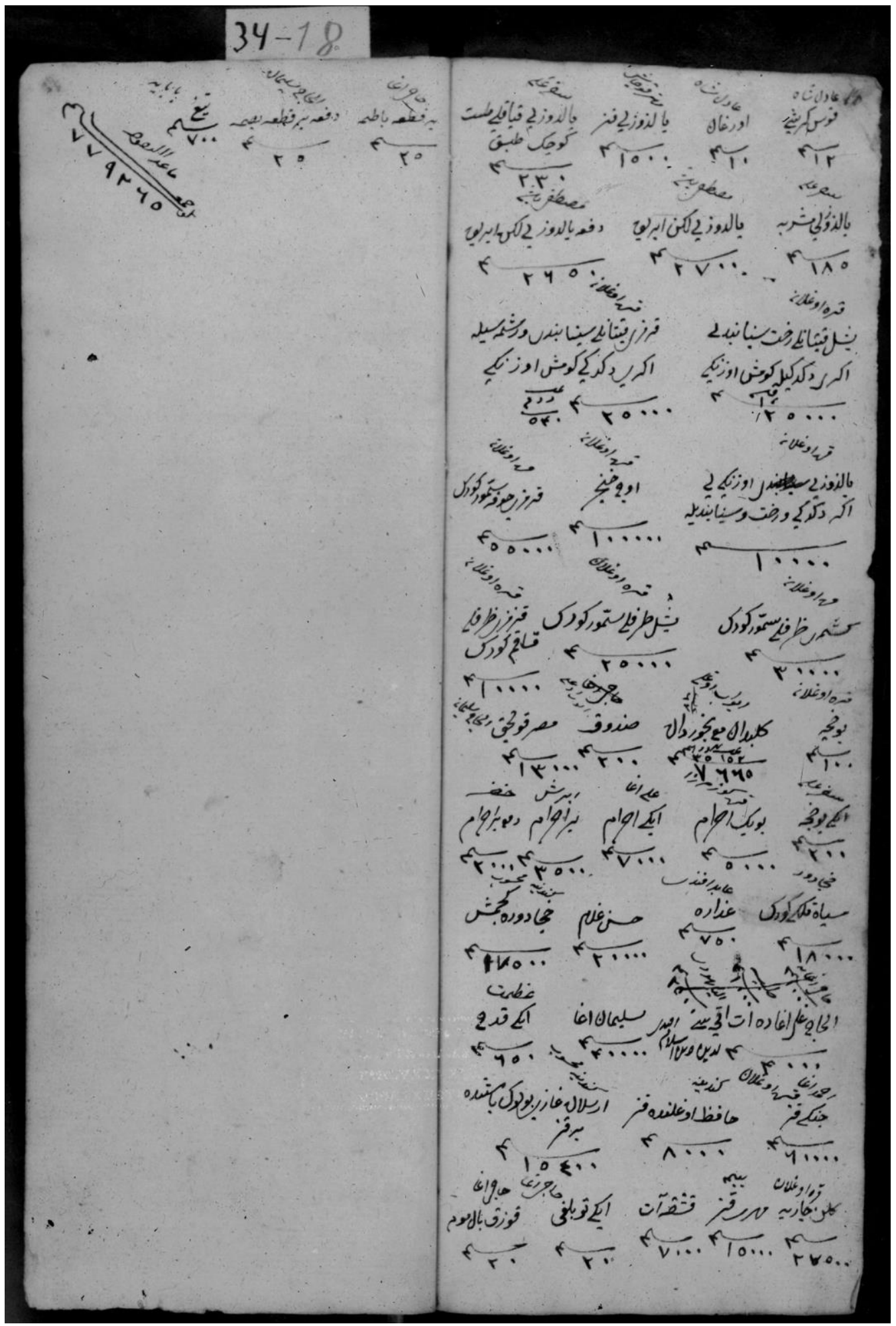

